\title{
An experimental study of the structure of a freshwater-saltwater interfacial mixing
}

\section{Étude expérimentale du mélange à l'interface eau-saumure}

\author{
H. O. Anwar and J. A. Weller
}

Hydraulics Research Station, Wallingford, England

\section{Introduction}

This paper describes the results of an experimental study of freshwater which flows two-dimensionally over a still pool of saltwater. This type of flow can be observed when heated cooling water is discharged from a power station horizontally onto the surface of a lake, reservoir $[4,6,12,30,31,33]$ or in an estuary where the outflow of freshwater mixes with underlying saltwater; the flux of brackish water increases with the distance downstream from the head of the estuary $[6,9,10,19]$. In these types of flow the depth of the lighter fluid at the mouth is usually high, being of the order of $2-3 \mathrm{~m}$; and the mouth densimetric Froude number (defined later) is about unity or less [4, 28, 36], indicating that the mixing process of the surface layer is dominated mainly by buoyancy rather than momentum. In most previous laboratory studies measurements were carried out for jet-type flow, for which the densi- metric Froude number was high with a shallow depth of flow at the inlet $[5,8,15,18]$. The object of the present investigation is to study the cases in which the densimetric Froude number is low, varying between 0.5 and 2 and, the depths of freshwater, which are relatively large, vary between $0.08 \mathrm{~m}$ and $0.12 \mathrm{~m}$. It is assumed that the flow structure and the turbulent mixing process that occur in this study are similar to those occurring in nature.

Expérimentally freshwater was released two-dimensionally from a wide channel onto the surface of stationary saltwater with density of $1025 \mathrm{~kg} / \mathrm{m}^{3}$ held in a wide, deep flume. During the experimental runs saltwater was supplied gently at a constant rate along the bottom of the flume in order to obtain a steady surface flow. Mean velocity and density profiles, together with their turbulence intensities, were measured at various sections downstream from the inlet. Entrainment was measured directly from saltwater supply (Fig. 1) and it was also determined from density profiles.

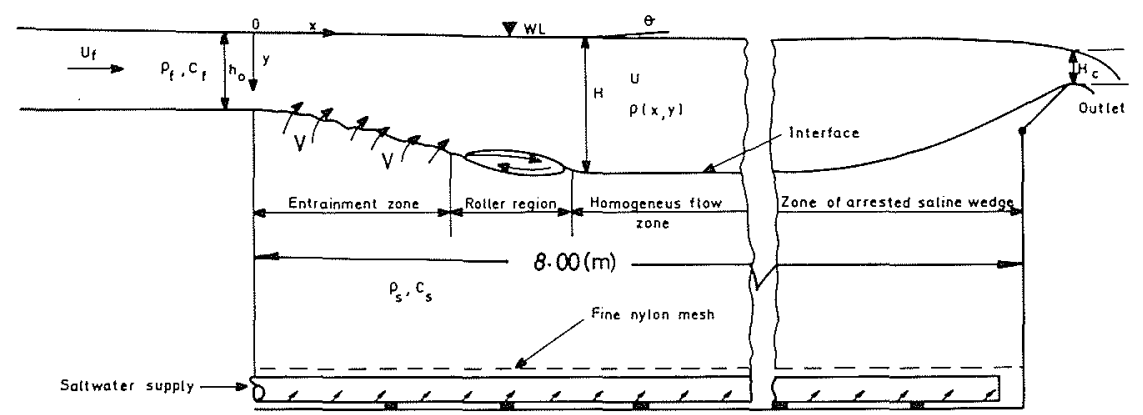

Figure 1 - Définition sketch of a two-dimensional surface layer flow.

Ecoulement bidimensionnel en surface : définitions.

LA HOUILLE BLANCHE $/ \mathrm{N}^{\circ}$ 6-1981 


\section{Symbols}

The following symbols are used in the paper :

$\begin{array}{ll}C_{i} & \text { Interfacial shear stress } \\ C_{s} & \text { Salt concentration } \\ E & \text { Entrainment coefficient } \\ f_{1}, f_{2} & \text { Similarity function (see equation } \\ F & \text { Froude Number } \\ F_{r} & \text { Densimetric Froude Number } \\ F_{x}, F_{y} & \text { Components of buoyancy } \\ H, \delta & \text { Layer thickness } \\ h_{0} & \text { Freshwater depth } \\ I_{0}-I_{4} & \text { Parameters (see equation (9)) } \\ R_{\mathrm{e}} & \text { Reynolds Number } \\ R_{\mathrm{i}} & \text { Richardson Number } \\ \theta & \text { Inclination angle } \\ \eta, \hat{\eta} & \text { Non-dimensional layer thickness } \\ \nu & \text { Kinematic viscosity } \\ \tau_{i} & \text { Interfacial shear stress }\end{array}$

\section{Analysis}

It is assumed that the motion in a flowing freshwater layer is steady, and that the features of the model, as shown in Figure 1 are similar to those of a 'density jump' studied by others $[9,12,17,19,30,33]$, namely consisting of three zones : 1 . the entrainment zone, 2 . roller region and 3 . the zone of homogeneous flow $[17,33]$. In the third zone the layer travels over the saltwater pool behaving much like free homogeneous flow over a rigid surface $[1,2]$. The appearance of these three zones depends on the inlet densimetric Froude number and also on the control height at the downstream outlet, which will be described later.

Let the Boussinesque approximation be made, namely that the density difference between the underlying saltwater and freshwater layer can be neglected except where multiplied by $g$, the acceleration due to gravity. Experimentally the temperature difference between the flowing layer and saltwater pool was kept very small so that all density variations are assumed to be caused by salinity differences. Thus the equations of motion for the flowing layer, in the co-ordinates system shown in Figure 1, can be written in the following form :

Momentum

$$
\begin{aligned}
U \frac{\partial U}{\partial x}-V \frac{\partial U}{\partial y} & =-\frac{1}{\rho_{f}} \frac{\partial p}{\partial x}-\frac{\overline{\partial u^{2}}}{\partial x}+\frac{\overline{\partial u v}}{\partial y}+F_{x} \\
0 & =\frac{1}{\rho_{f}} \frac{\partial p}{\partial y}+\frac{\overline{\partial v^{2}}}{\partial y}-\frac{\overline{\partial u v}}{\partial x}-F_{y}
\end{aligned}
$$

Continuity

$$
\frac{\partial U}{\partial x}-\frac{\partial V}{\partial y}=0
$$

Note that in equation (2) the advection terms, being small, are neglected.

In equations (1) - (3) $U$ and $V$ are the respective mean velocity with their velocity fluctuation $\bar{u}$ and $\bar{v}$ in the direction of $x$ and $y$ co-ordinates respectively, $p$ is the pressure, $\rho_{f}$ the mass density of flowing layer and finally $F_{x}$ and $F_{y}$ are the components of the buoyancy force in the $x$ and $y$ direction. In the above equations it is assumed that the viscous shear stress is negligible in comparison with the turbulent shear stress, so that the terms expressing the components of viscous stress are not included.

Equation (1) will be integrated with respect to $y$ to give the following equation by making use of equation (3) and assuming $\frac{\overline{\partial u^{2}}}{\partial x} \ll \frac{\overline{\partial u v}}{\partial y}$. This can be deduced from the results of turbulence measurement shown in Figure 4 indicating that the variation of $\overline{u^{2}}$ with $x$ is negligible, furthermore measurement showed that the variation of mean velocity near the inlet was constant, elsewhere very small for the experimental range presented here.

$$
\begin{aligned}
& \frac{\tau_{i}}{\rho_{f}}=-\int_{0} \frac{H}{\partial x} d y+ \\
& \quad+\left.U V\right|_{0} ^{H}-\frac{1}{\rho_{f}} \int_{0}^{H} \frac{\partial p}{\partial x} d y+\int_{0}^{H} F_{x} d y
\end{aligned}
$$

where $\tau_{i}=-\rho_{f} \overline{u v}$ is the average Reynolds shear stress at the interface. From the definition of the interfacial shear stress $\tau_{i}$, it can be seen that a motion in the underlying saltwater pool is necessary to account for the momentum exchange taking place between upper and lower layer, $[12,19]$. The existence of such a drift in the saltwater layer was observed previously, $[17,31]$; it was also observed in the present experimental study as will be described later. In equation (4) $V$ is the entrainment velocity at the interface (see Fig. 1). The pressure $p$ can be calculated from equation (2) by assuming that $\overline{\partial v^{2}} / \overline{\partial y}$, and the variation of the Reynolds stress in horizontal direction are negligible. These, together with the above verified assumption, i.e. $\overline{d u^{2}} / \overline{d x}$ being small, indicate that the turbulence in the flowing layer is uniform, hence

$$
\frac{1}{\rho_{f}} \frac{\partial p(x, y)}{\partial y}=F_{y}
$$

which can be integrated in the form

$$
\begin{aligned}
p(x, y)=\rho_{f} & \int_{0}^{y} F_{y} d y= \\
& =g \int_{0}^{y} \Delta \rho(x, s) \operatorname{Cos} \theta d s+p_{0}(x)
\end{aligned}
$$

in which $\Delta \rho(x, y)=\rho_{s}-\rho(x, y)$ where $\rho(x, y)$ is the local mass density of the flowing layer, $\theta$ is the inclination angle of the free surface and $p_{0}(x)$, being a function of $x$ alone $[1,2]$, is equal to the atmospheric pressure and is a constant. By differentiating equation 
(6) with respect to $x$ and substituting the result together with the value for the buoyancy component

$$
F_{x}=g \frac{\Delta \rho(x, y)}{\rho_{f}} \sin \theta
$$

in equation (4) the following expression will be obtained

$$
\begin{aligned}
\frac{\tau_{i}}{\rho_{f}}=-\int_{0}^{H} \frac{\partial U^{2}}{\partial x} d y+\left.U V\right|_{0} ^{H}+ \\
+g \operatorname{Cos} \theta \int_{0}^{H} \int_{0}^{y} \frac{1}{\rho_{f}} \frac{\partial \Delta \rho(x, s)}{\partial x} d s d y \\
+g \operatorname{Sin} \theta \int_{0}^{H} \frac{\Delta \rho(x, y) d y}{\rho_{f}}
\end{aligned}
$$

Experimental results (presented later) show that velocity and density profiles are geometrically self-similar, i.e. the velocity and density profiles can be expressed in terms of non-dimensional functions such as $f_{1}(\eta)$ and $f_{2}(\eta)$. The argument $\eta$ represents vertical distance y made non-dimensional with an $x$-dependent characteristic dimension such as $H$, representing the thickness of the flowing layer (see Fig. 1). It was found from experimental results that the maximum velocity, $U_{m}$, occurring near the free surface, the density differences $\Delta \rho_{m}$ between the saltwater and freshwater and the thickness $H$ are the suitable scales which can be used for velocity and density distribution, i.e.

and

$$
U(x, y)=U_{m}(x) f_{1}(\eta)
$$

$$
\Delta \rho(x, y)=\Delta \rho_{m}(x) f_{2}(\eta)
$$

where $\eta=y / H$ and $\Delta \rho_{m}=\rho_{s}-\rho_{f}$. Note that if $\rho_{f}$ in the moving layer differs from that of freshwater its functional variation with respect to $x$ must be defined.

By substituting expression (8) into equation (7) and assuming $\tau_{i_{i}}=1 / 2\left(C_{i} \rho_{f} U_{m}^{2}\right)$ where $1 / 2 C_{i}$ is the coefficient of interfacial friction, the following equation will be obtained :

$$
\begin{aligned}
& \frac{\tau}{\rho_{f} U_{m}^{2}}=\frac{1}{2} C_{i}= \\
& =\left(I_{1}-I_{4} R_{i} \operatorname{Cos} \theta\right) \frac{d H}{d x}-I_{0} \frac{H}{U_{m}^{2}} \frac{d U_{m}^{2}}{d x}+\left.E f_{1}(\eta)\right|_{0} ^{1}+ \\
& \quad+I_{3} \frac{H}{F^{2}} \frac{\Delta \rho_{m}}{\frac{\rho_{f}}{d x}} \operatorname{Cos} \theta+I_{2} R_{i} \operatorname{Sin} \theta
\end{aligned}
$$

in which

$$
\begin{aligned}
& I_{0}=\int_{0}^{1} f_{1}^{2}(\eta) d \eta, I_{1}=\left.\eta f_{1}^{2}(\eta)\right|_{0} ^{1}-\int_{0}^{1} f_{1}^{2}(\eta) d \eta, \\
& I_{2}=\int_{0}^{1} f_{2}(\eta) d \eta, I_{3}=\int_{0}^{1}\left[\int_{0}^{\eta} f_{2}(\sigma) d \sigma\right] d \eta, \\
& I_{4}=\int_{0}^{1} \int_{0}^{\eta} \frac{\sigma d f_{2}(\sigma)}{d \sigma} d \sigma d \eta
\end{aligned}
$$

In equation (9) $E=T / U_{m}$ is the coefficient of entrainment,

$$
F^{2}=\frac{U_{m}^{2}}{g H}, \quad \hat{R}_{i}=\frac{g\left(\Delta \rho_{m} / \rho_{f}\right) H}{U_{m}^{2}}
$$

is the global Richardson number and finally $\sigma=y / H, y$ representing a vertical co-ordinate in salt profiles (described later). The value of $1 / 2 C_{i}$ will be evaluated later when various terms in equation (9) have been determined from the experimental results.

\section{Experiment}

The experiments were carried out in a glass-walled flume of rectangular section $0.92 \mathrm{~m}$ wide, $0.92 \mathrm{~m}$ deep and $13 \mathrm{~m}$ long. The flume was divided into a freshwater channel $0.20 \mathrm{~m}$ deep and $2.5 \mathrm{~m}$ long and a saltwater reservoir $8 \mathrm{~m}$ long (see Fig. 1). A weir with a smooth entrance and a stilling basin was fitted at the upstream end of the freshwater channel. The stilling basin together with honeycombs and screens provided a uniform twodimensional freshwater flow as confirmed by the measured velocity profile at a section near the channel exit. In each experiment the flume was filled with saltwater, whose concentration was $4 \%$, using sodium nitrate in order to minimise corrosion in the system. The mass density of saltwater was $\rho_{s}=1025 \mathrm{~kg} / \mathrm{m}^{3}$, and the temperature of saltwater and freshwater was kept almost the same throughout the experimental runs. In order to maintain a steady state during each experimental run saltwater had to be added to the flume to compensate for that lost by entrainment. The extra saltwater was made in an auxiliary tank provided with a centrifugal pump to deliver the saltwater into a constant header tank, which in turn was connected, via a variable orifice meter, to 4 pipes $0.1 \mathrm{~m}$ diameter, laid horizontally along the floor of the flume (see Fig. 1). The pipes were provided with holes, $0.1 \mathrm{~m}$ apart, which faced down towards the flume floor and the saltwater was supplied continuously through the holes. The pipes were covered with a fine meshed nylon sheeting; this arrangement produced a gentle flow of saltwater into the flume.

\section{Velocity}

Mean velocity profiles were measured at various sections along the centre-line of the flume with a miniature current meter $10 \mathrm{~mm}$ diameter. Furthermore an attempt was made to determine turbulence intensity, but a reliable result was obtained only when the densimetric Froude number

$$
F_{r}=\frac{U_{f}}{\sqrt{g\left(\Delta \rho_{m} / \rho_{f}\right) h_{0}}}=0.8
$$

where $U_{f}$ is the mean freshwater velocity with depth $h_{0}$ measured near the exit of the freshwater channel (see Fig. 1). The measured velocity profiles were made dimensionless by taking the maximum velocity $U_{m}$ occurring at the free surface and the depth $H$ (see Fig. 1) as a velocity and a length scale respectively. 


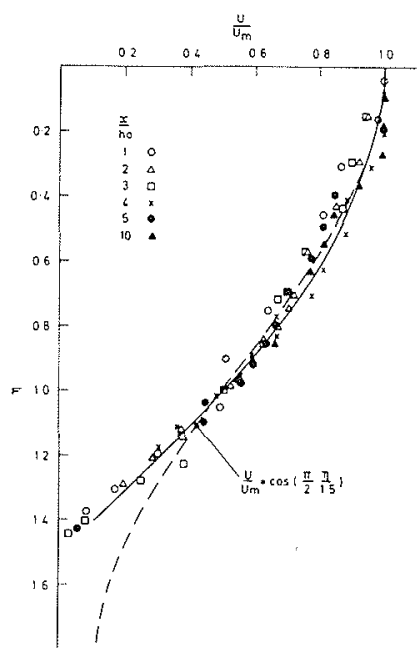

Figure 2 - Mean velocity profile in the entrainment zone, ... - Gaussian Profile.

Répartition des vitesses moyennes dans la zone d'entraînement.

The depth $H$ was measured from the free surface to a point where the mean velocity $U$ is about $1 / 2 U_{m}$. Figure 2 shows a typical non-dimensional velocity profile in the entrainment zone. In this figure is also shown an empirical function fitted to the measured data expressed in the following form

$$
\frac{U}{U_{m}}=\operatorname{Cos}\left(\frac{\pi}{2} \frac{\eta}{1.5}\right)
$$

It was found that the same expression is applicable to the measured data when $F_{r}=0.77,1.06,1.26$ and 1.85. In Figure 2 is also shown the velocity distribution of a Gaussian profile obtained by others [5, 9] for surface jets when $F_{r} \geqslant 2$. It can be seen that the measured profile does not indicate a Gaussian form for $\eta>1$ and $F_{r}<2$.

Similarly the measured mean velocity in the zone of homogeneous flow was made dimensionless using $U_{m}$ and $H$-scale and the result is shown in Figure 3, a similar profile was obtained for other value of $F_{r}$. In Figure 3

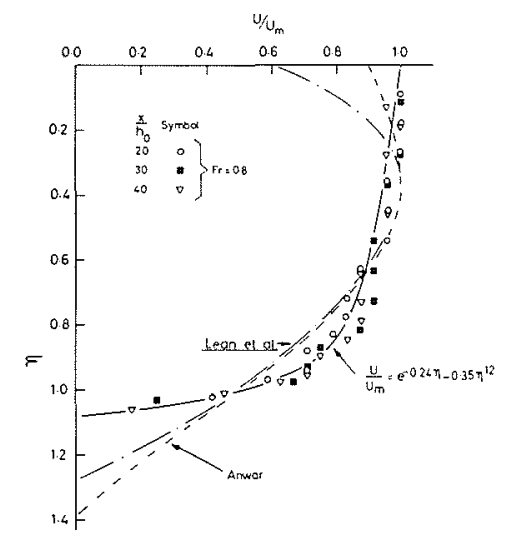

Figure 3 - Mean velocity profile in the zone of homogeneous flow.

Répartition des vitesses moyennes dans la zone d'écoulement homogène. is also shown an empirical fitted curve in the following form

$$
\frac{U}{U_{m}}=e^{-0.24 n}-0.35 \eta^{1 / 2}
$$

In Figure 3 are also shown empirical fitted curves obtained by others $[1,2,17]$ for comparison. Previous studies (Anwar [1, 2] and Lean et al. [17]) showed that the maximum velocity $U_{m}$ does not occur at the free surface as was the case in the present study. Moveover it can be seen that their profiles $[1,2,17]$ appeared to be symmetrical about the position of $U_{m}$. It is believed that the appearance of $U_{m}$ below the free surface in the zone of homogeneous flow was due to a large depth-towidth ratio; this was 0.1 in the present study, representing a two-dimensional flow.

It was observed that there was a general movement in the saltwater flume in the mean flow direction, similar to those observed by Lean et al. [17] and Stefan [31]. An attempt was made to measure the drift, but it was too small to be measured with a sufficient degree of accuracy. The injection of dye across the saltwater depth indicated that the dye motion was almost zero near the nylon sheeting (see Fig. 1), it increased rapidly near the interface. It is believed that a similar motion will occur in prototype because of the interfacial shear stress $[13,21]$. Furthermore it was observed that a roller region (see Fig. 1) appeared when $F_{r}>0.8$ and it disappeared when $F_{r} \leqslant 0.8$. In this case the flow of the surface layer behaved much like 'flooded density jump' investigated by Wilkinson et al. [37] and others $[28,31]$,

The turbulence intensity $(\stackrel{\bar{u}}{\bar{u}})^{1 / 2} / \bar{U}$, using a constant temperature hot-film anemometer (CTA-Thermo Systems TSI model 1054A) was determined in the flow direction when $F_{r}=0.8$ and $R_{e}=U_{f} h_{0} / \nu=11300$ where $\nu$ is the kinematic viscosity of the freshwater. The measurement was carried out at three downstream sections where $x / h_{0}=1,2$ and 3 . The measured data were made dimensionless using local mean velocity $\vec{U}$ as a scale velocity and the results are shown in Figure 4. It can be seen that the turbulence intensity, being small in the major part of the surface layer, increases rapidly towards the interface behaving much

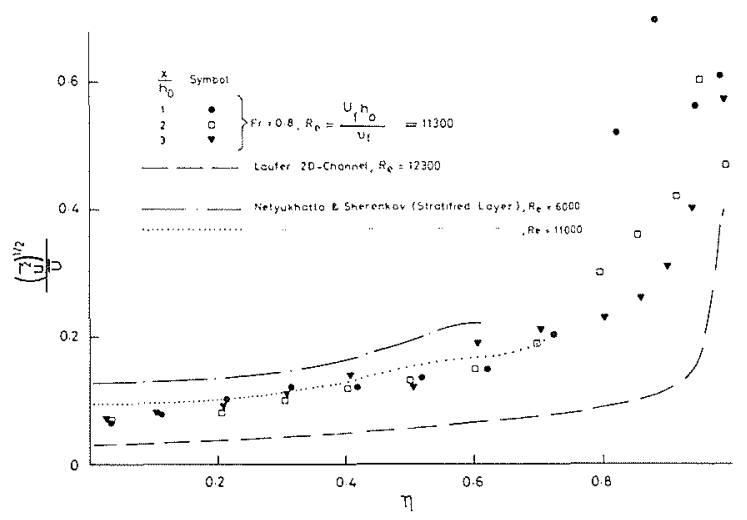

Figure 4 - Turbulence intensity profiles. Répartition de l'intensité de la turbulence. 
like Laufer's [16] two-dimensional channel flow. In Figure 4 is also shown the turbulence intensity profile obtained by Netyukhaylo et al. [24] for a surface layer flow similar to that presented here; it agrees reasonably well with that obtained in the present investigation for almost the same value of $R_{e}$. The profiles shown in Figure 4 indicates that the turbulence intensity increases as the Reynolds number decreases, a result that agrees with those obtained in a two-dimensional homogeneous channel flow [16].

\section{Mean concentration}

The mean concentration profile was determined using a conventional conductivity probe designed at the Hydraulics Research Station. The diameter of the probe was $5 \mathrm{~mm}$ tapering to $1.5 \mathrm{~mm}$ at the electrode. The probe was connected to a ' $U V$ ' chart recorder and an integrated voltmeter to obtain mean and rms value of salt concentration respectively. The measured mean concentration profiles were made dimensionless using $\delta$ as a characteristic depth (discussed later) at which the ratio of concentration deficit

$$
\frac{C}{C_{m}}=\frac{C_{s}-C_{p}}{C_{s}-C_{f}}=\frac{1}{2}
$$

where $C_{s}$ and $C_{f}$ are the concentration of the saltwater and freshwater respectively; $C_{p}$ is the measured concentration of saltwater at a point. The calculated values of $C / C_{m}$ were plotted against $\hat{\eta}=s / \delta$ and Figure 5 shows a typical result for $F_{r}=0.8$; similar profiles were obtained for other values of $F_{r}$. In Figure 5 is also shown Iwasaki et al. [11] results together with an empirical fitted curve to the measured data expressible in the following form

$$
\frac{C}{C_{m}}=\frac{1}{2} \operatorname{erfc}[A(\hat{\eta}-1]
$$

The constant $A$ in equation 15 was found to be 30 for the profiles in the entrainment zone and 40 in the zone of homogeneous flow. A similar temperature profile was measured by Stefan et al. [30] in their experiment on three-dimensional surface plume when $F_{r}<2$.

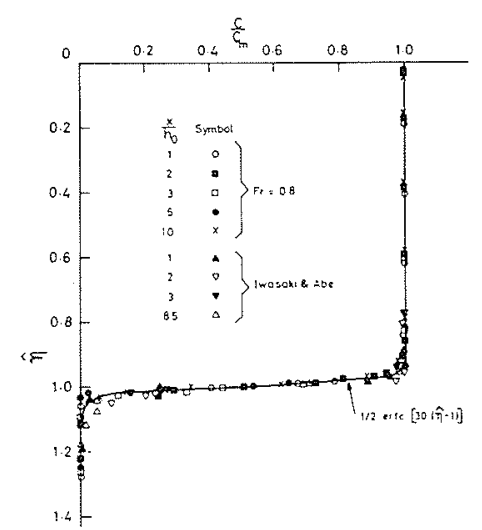

Figure 5 - Mean salt concentration profile. Répartition de la concentration saline moyenne.

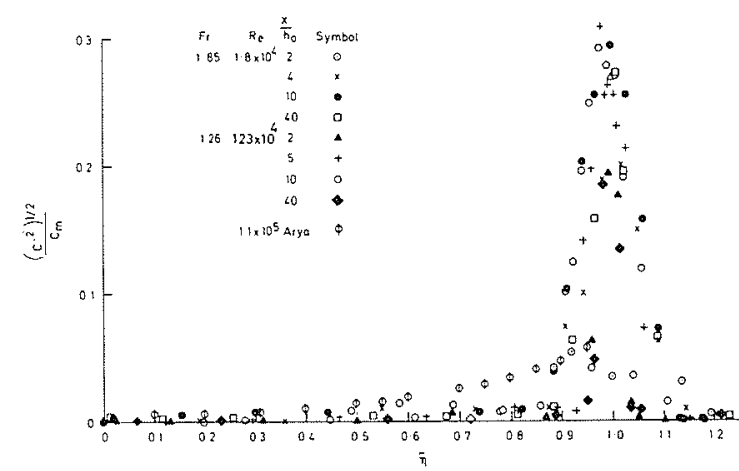

Figure 6 - Turbulence intensity of salt fluctuation. Intensité des fluctuations turbulentes de concentration.

The rms value of salt fluctuation $\left(\bar{C}^{2}\right)^{1 / 2}$ was made dimensionless using $C_{m}$, salt concentration of underlying saltwater, and $\delta$ as characteristic scale; the results for $F_{r}=0.8$ and 1.85 at various downstream sections are shown in Figure 6. Similar profiles were obtained for other values of $F_{r}$ but are not shown in Figure 6 to avoid cluttering the diagram. Figure 6 shows that the turbulence intensity profiles of salt fluctuation behave similar to that of a horizontal boundary layer along a heated flat-plate investigated by Arya [3] indicating a maximum at $\tilde{\eta}=1$. Figure 6 further shows that the turbulence intensity profile of the present investigation increases slightly with the increase of $F_{r}$, which increases with the increase of Reynolds number $R_{e}$.

\section{The layer thickness}

The layer thickness $\delta$ was determined from the salt concentration profiles, and is measured from the free surface to the point where $C / C_{m}=1 / 2$. It was found that at this point $(\hat{\eta}=1)$ the turbulence intensity of salt fluctuation became a maximum (see Fig. 6). This in fact is a point at which the salt fluctuation undergoes a distinct jump and the gradient of mean salt concentration profile is a maximum (see Fig. 5). The measured $\delta$ in the three zones shown in Figure 1 was made nondimensional using freshwater depts $h_{0}$ and the results were plotted against $x / h_{0}$ in Figure 7 for

$$
0,5 \leqslant F_{r} \leqslant 1.85 \text {. }
$$

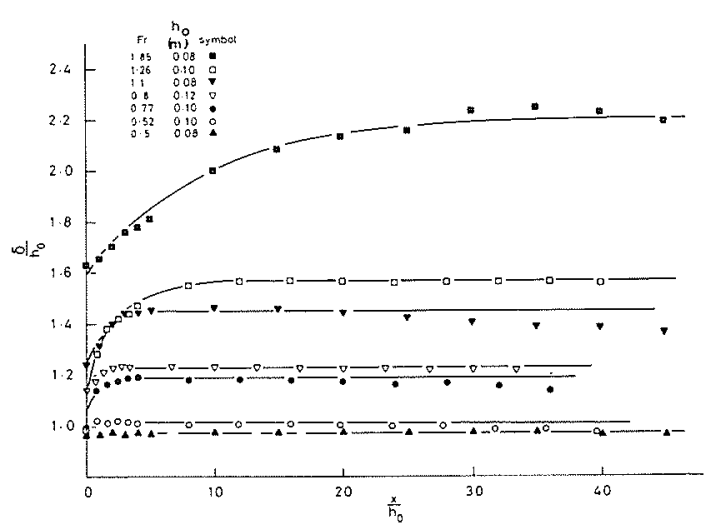

Figure 7 - Surface layer growth determined from salt concentration profiles:

Epaisseur de la couche de surface déterminée à partir des répartitions de concentration. 
Figure 7 shows that the length of the entrainment zone increases with the increase of $F_{r}$. In this zone it was observed that, immediately downstream from the freshwater channel exit, the surface layer behaves much like a two-dimensional surface jet, entraining a great deal of the underlying saltwater, and the thickness $\delta$ grows linearly with the distance $x$, (the linear part of curves shown in Fig. 7). The length of the jet-type region depending on $F_{r}$ was rather short, i.e. $x / h_{0}<3$ when $F_{r}<0.7$, it increases with the increase of $F_{r}$ so that $x / h_{0}<10$ when $F_{r}$ varied between 0.8 and 1.85 . The entrainment zone almost disappeared, and the flowing layer behaved similar to that of a flooded density jump [37] when $F_{r} \leqslant 0.52$. Figure 7 further shows that the thickness $\delta$ remains unchanged in the zone of homogeneous flow. It was found that in the zone of entrainment the boundary layer growth due to mixing process is larger than $H$ due to the shear layer $[1,2]$. In this zone $\delta / H$ ratio increases slightly with the increase of $F_{r}$ as shown in Table I for $5 \geqslant x / h_{0} \geqslant 0$. The $\delta / H$ ratio was not determined for $x / h_{0}>5$.

\begin{tabular}{|c|c|c|c|c|c|}
\hline \multicolumn{6}{|c|}{ Table I } \\
\hline \multicolumn{7}{|c|}{ Non-dimensional boundary layer $\delta / H$} \\
\hline$F_{r}$ & 1 & 2 & 3 & 4 & 5 \\
\hline 0.77 & 1.15 & 1.142 & & 1.086 & 1.088 \\
0.80 & 1.364 & 1.322 & 1.293 & & 0.925 \\
1.1 & 1.222 & 1.293 & 1.206 & 1.230 & \\
1.26 & 1.365 & 1.392 & 1.429 & & 1.42 \\
1.85 & 1.620 & 1.661 & 1.645 & 1.480 & \\
\hline
\end{tabular}

\section{Entrainment coefficient $E$}

The entrainment velocity $V$ (see Fig. 1) was calculated from salt concentration profiles using the following expression [34]

$$
V=q_{0} \frac{C_{S}}{\left(C_{s}-C_{\text {mean }}\right)^{2}} \frac{d C_{\text {mean }}}{d x}
$$

in which $q_{0}$ is freshwater inflow per unit width and $C_{\text {mean }}$ is the mean value of salinity calculated from salinity profiles. It was found that saltwater flux $q$ calculated from equation (17) agreed rasonably well with the direct measurement of saltwater supply (see Fig. 1). The coefficient of entrainment

$$
E=V / U_{\text {mean }},
$$

where $U_{\text {mean }}$ is the mean value of velocity at a section, was plotted against the global Richardson number in Figure 8. In Figure 8 are also shown values of the entrainment $E$ obtained by others [1,2, 5, 8, 18, 29, 34] $A$ best fitted empirical curve to the measured data expressible in the following form shown as a solid line in Figure 8, i.e. :

$$
E=\frac{0.1}{\left(1+63 R_{i}^{2}\right)^{3 / 4}}
$$

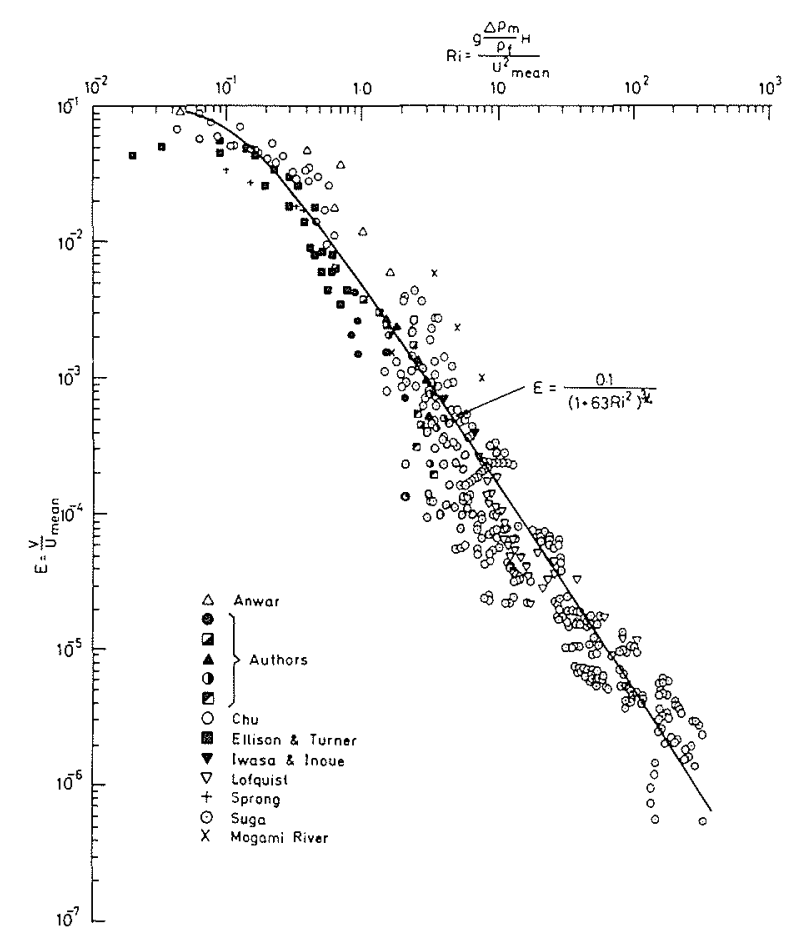

Figure 8 -Variation of entrainment coefficient with Richardson number.

Variation du coefficient d'entrainement en fonction du nombre de Richardson.

It can be seen that the coefficient $E$ for the range of $R_{i}$ shown in Figure 8 cannot be expressed as a single Power law, it does howeter tend to the form

when $R_{i}>7$.

$$
E \approx 0.0045 R_{i}^{-3 / 2}
$$

An attempt was made to measure the slope of the free surface using a precision point-gauge, but is was found that the slope was too small to be measured accurately. The results of measurementi, however, showed that there is a rise in water level immediately downstream from the freshwater inlet (section 0, see Fig. 1), mainly due to an increase in potential energy caused by the mixing process in the entrainment zone. The maximum rise of water level was about $1.3 \mathrm{~mm}$ over a length of $x=1.5 \mathrm{~m}$ giving a negative slope when $F_{r}=1.85$. The water level then fell about $0.15 \mathrm{~mm}$ ever a length of $x=4 \mathrm{~m}$. The rise in water level, as to be expected, became progressively less as $F_{r}$ decreased and it was $0.25 \mathrm{~mm}$ over a length of $x=0.5 \mathrm{~m}$ when $F_{r}=0.52$, beyond which the fall in water level was less than the accuracy of the point-gauge. From the above results in can be concluded that, as mentioned previously, $\sin \theta \approx 0$ and $\cos \theta=1$. The salinity measurements for all values of $F_{r}$ showed that salt concentration near the surface was very small and a similar result was obtained by Iwasa et al. [10], henre it can be concluded that $d \Delta \rho_{m} / d x \approx 0$.

\section{The coefficient of interfacial shear stress}

From equation (9) the following equation describing the coefficient of interfacial shear stress for the cases 
studied here i.e. $\theta \approx \frac{d \Delta \rho_{m}}{d x} \approx 0$ can be written

$\frac{1}{2} C_{i}=\left(I_{1}-I_{4} R_{i}\right) \frac{d H}{d x}-I_{0} \frac{H}{U_{m}^{2}} \frac{d U_{m}^{2}}{d x}+\left.E f_{1}(\eta)\right|_{0} ^{1}$

The value of $I_{0}-I_{4}$ for the entrainment zone and the zone of homogeneous flow were evaluated from measured data and the results are given in Table II. In table II are also shown the I's values for comparison when the velocity and salt concentration profiles are Gaussian.

The terms in the right hand side of equation (19) and hence the coefficients $1 / 2 C_{i}$ were evaluated for these zones as shown in Figure 9, in which are also shown the measured data obtained by others $[18,20,22]$. Figure 9 shows that the coefficient $1 / 2 C_{i}$ becomes independent of the Richardson number when $R_{i}>5$. In this case the entrainment becomes negligible (see Fig. 8) and the surface layer flows over the saltwater pool behaving much like free homogeneous flows over a smooth rigid surface, for which the coefficient $1 / 2 C_{i}$ can be approximated to the following form [27]

$$
\frac{1}{2} C_{i}=0.023 R_{e}^{-1 / 4}
$$

which is applicable to the cases where the layer Reynolds number $R_{e}=\frac{U_{\text {mean }} H}{\nu}<10^{5}$.

At low Reynolds number i.e. $R_{e}<5000$ the results of a study carried out by Macagno et al. [20] indicate that the coefficient of interfacial shear stress $1 / 2 C_{i}$ is a function of $R_{i}$; it decreases with the increase of $R_{i}$. This may be due to the increased stability of the density gradient at the interface.

\section{Stratified flow with little entrainment}

Here an attempt will be made to explore the applicability of equation (19) to the type of flow in which mixing between the upper layer and underlying saltwater is very small, the case of an arrested saline wedge in an estuary. For this type of flow equation (19) with $E=\theta \approx 0$ will take the following form

$$
\frac{1}{2} C_{i}=\left(I_{1}-I_{4} R_{i}\right) \frac{d H}{d x}-I_{0} \frac{H}{U_{\text {mean }}^{2}} \frac{d U_{\text {mean }}^{2}}{d x}
$$

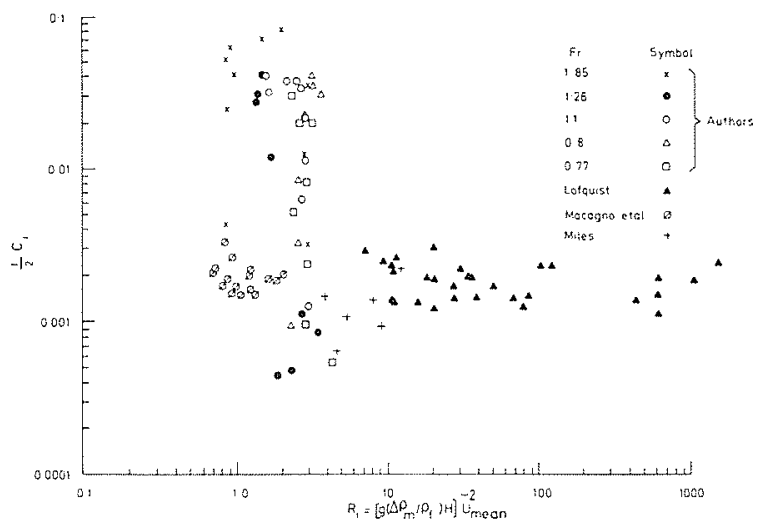

Figure 9 - Variation of interfacial skin friction coefficient with Richardson number.

Variation du coefficient de frottement à l'interface en fonction du nombre de Richardson.

which shows that the coefficient $1 / 2 C_{i}$, depending on $R_{i}$, varies with the growth rate of the layer thickness and its spatial acceleration. From equation (21) and values of $I_{1}$ and $I_{4}$ given in Tablè II, it can be deduced that for $R_{i}<\frac{I_{1}}{I_{4}}$ the growth rate $\frac{d H}{d x}$ is negative indicating that the flowing layer along its course becomes thinner. This means that, since $\Delta \rho_{m} / \rho_{f}$ remains unchanged, the Richardson number $R_{i}$ eventually becomes sufficiently small for the onset of the instability of a KelvinHelmholtz type $[1,2]$. This type of instability causes the development of a highly turbulent flow associated with a large amount of the underlying fluid to be entrained across the interface into the flowing layer [2]. Although the experimental setup presented here was not designed to study this type of flow, it was noticed that the surface layer, because of the outlet control gate (see Fig. 1) becomes progressively thinner downstream from the zone of homogeneous flow, but the instability mentioned in the above was never observed. Various terms af equation (21) were evaluated for this part of the flow and the results are shown in Table III, indicating that the $1 / 2 \quad C_{i}$ is small for such a flow without entrainment.

There are types of flow in which the density difference between the flowing layer and the underlying saltwater is small i.e. $R_{i} \approx 0$. For this type of flow equation (21) shows that the coefficient $1 / 2 C_{i}$ becomes independent of the Richardson number. The flowing layer behaves much like free homogeneous flow over a rigid boundary with varying depth.

\begin{tabular}{|c|l|c|c|c|c|c|c|}
\hline \multicolumn{7}{|c|}{ Table II } \\
\hline$F_{r}$ & $h_{0}(m)$ & $x / h_{0}$ & $I_{0}$ & $J_{1}$ & $J_{2}$ & $J_{3}$ & $/_{4}$ \\
\hline 0.5 & 0.08 & $5-15$ & 0.6971 & -0.1518 & 0.9975 & 0.49997 & -0.002425 \\
0.52 & 0.1 & $5-15$ & 0.7483 & -0.3949 & 0.9997 & 0.49995 & -0.00371 \\
0.77 & 0.12 & $20-30$ & 0.7847 & -0.2839 & 0.9878 & 0.49947 & -0.01113 \\
0.8 & 0.1 & $20-40$ & 0.7077 & -0.144 & 0.9938 & 0.49964 & -0.00908 \\
1.1 & 0.08 & $20-30$ & 0.6978 & -0.1534 & 0.9878 & 0.49947 & -0.01113 \\
1.26 & 0.1 & $20-40$ & 0.7286 & -0.42243 & 0.9902 & 0.49964 & -0.009081 \\
1.85 & 0.12 & $20-40$ & 0.6499 & -0.4069 & 0.9762 & 0.49832 & -0.0102 \\
Gaussian Profiles & & & 0.5717 & -0.3217 & 0.8085 & 0.3728 & -0.0121 \\
\hline
\end{tabular}




\begin{tabular}{|l|c|c|c|c|c|c|c|}
\hline \multicolumn{7}{|c|}{ Table III } \\
\hline \multicolumn{1}{|c|}{$F_{r}$} & 0.5 & 0.52 & 0.77 & 0.8 & 1.1 & 1.126 & 1.85 \\
\hline $\begin{array}{l}\text { Interfacial } \\
\text { slope }\end{array}$ & -0.00116 & -0.00137 & -0.00476 & -0.00337 & -0.00235 & -0.0038 & -0.005 \\
$x / h_{0}$ & $40-70$ & $30-60$ & $40-60$ & $40-70$ & $50-90$ & $40-70$ & $50-90$ \\
$1 / 2 C_{i} x$ & 0.151 & 0.551 & & 0.404 & 0.27 & 1.41 & 1.54 \\
$10^{+3}=$ & & & 0 arious terms for arrested saline wedge \\
\hline
\end{tabular}

\section{Acknowledgements}

The work described here was carried out as part of the research programme of the Hydraulics Research Station, and is published with the permission of the Director of Hydraulics Research. The authors are grateful to Drs. T.J. Weare and G.V. Miles for their interest and useful suggestions.

\section{References}

[1] ANWAR H.O. - The Flow Structure in the Front of a Moving Surface Layer. Ingenieur Archiv., 1977, 46, pp. 143-156.

[2] ANWAR H.O. - Measurements on Entrainment through a Front. Second International Symposium on Stratified Flows, Trondheim, 24-27 June, 1980.

[3] ARYA S.P.S. - Buoyancy Effects in a Horizontal FlatPlate Boundary Layer. J. Fluid Mech., 1975, Vol. 68, Part 2, pp. 321-343.

[4] BRYCE J.B. and ELLIOTT R.V. - Thermal Plume Measurements in Lake Ontario and Resulting Phenomenological. I.S.S.F., Novosibirks, 1972, pp. 145-160.

[5] CHU V.H. and VANVARI M.R. - Experimental Study of Turbulent Stratified Shearing Flow. Proc. A.S.C.E., 1976 , Vol. 102, No. HY6, pp. 691-706.

[6] DYER K.R. - Estuaries : A Physical Introduction. John WILEY \& Sons, 1973 , pp. 4-18.

[7] ELLIOTT R.V. and HARKNESS D.G. - A Phenomenological Model for the Prediction of Thermal Plumes in Large Lakes. Proc. 15th Conf. Great Lakes Res., 1972, pp. 544-564.

[8] ELLISON T.H. and TURNER J.S. - Turbulent Entrainment in Stratified Flows. J. Fluid Mech., 1959, Vol 6, Part 3, pp. 423-448.

[9] HARLEMAN D.R.F. - Heat Disposal in Water environment. Proc. A.S.C.E., 1975, Vol. 101, No. HY9, pp. 1120-1138.

[10] IWASA Y. and INOUE K. - Interfacial Mixing in TwoLayered System of Fresh and Salt Water. Memoirs Faculty of Eng., Kyoto Univ., 1970, Vol. 32, No 1, pp. 23-30.

[11] IWASAKI T. and ABE T. - Turbulence in the Weakly Mixing Zone of the Interface. Coastal Eng. in Japan, 1972, Vol. 15, pp. 141-151.

[12] KOH R.C.Y. - Two-Dimensional Surface Warm Jets. Proc. A.S.C.E., 1971, Vol. 97, No. HY6, pp. 819-836.

[13] KOH R.C.Y. - Closure, Two-Dimensional Surface Warm Jets. Proc. A.S.C.E., 1972, Vol. 98, No, HY11, pp. 20382039.

[14] KULLENBERG G. - Entrainment Velocity in Natural Stratified Vertical Shear Flow. Estuarine and Coast Marine S.C., 1977, 5, pp. 329-338.

[15] LAL P.B.B. and RAJARATNAM N. - An Experimental Study of Bluff Buoyant Turbulent Surface Jets. J. Hydr. Research, 1977, Vol. 15, No. 3, pp.261-275.

[16] LAUFER J. - Investigation of Turbulent Flow in a TwoDimensional Channel. Report No 1053, N.A.C.A., 1951. Washington D.C.
[17] LEAN G.H. and WHILLOCK A.F. - The Behaviour of a Warm Water Layer Flowing over Still Water. Proc. of 11 th Congress I.A.H.R, 1965, Vol 2, No. 9 Leningrad, pp. 1-2.

[18] LOFQUIST K. - Flow and Stress near an Interface Between Stratified Liquids. The Physics of Fluid, 1960, 3, pp. 158-175.

[19] LONG R.R. - Circulation and Density Distribution in a Deep Strongly Stratified Two-Layer Estuary. J. Fluid Mech., 1975, Vol. 71, pp. 529-540.

[20] MACAGNO E.O. and ROUSE H. - Interfacial Mixing in Stratified Flows. Proc. A.S.C.E., 1961, Vol. 87, No. EM5, pp. 55-81.

[21] MEHROTRA S.C. - Discussion, Experimental Study of Turbulent Stratified Shearing Flow. Proc. A.S.C.E., 1977, Vol. 103, No. HY 4, pp. 463-464.

[22] MILES G.V. - Tiber Pollution Study. Stage 1, Report No. EX 773, 1977, Hydraulics Research Station Wallingford, England.

[23] MOTZ L.H. and BENEDICT B.A. - Surface Jet Model for Heated Discharges. Proc. A.S.C.E., 1972, Vol. 98, No. HY1, pp. 181-199.

[24] NETYUKHAYLO A.P. and SHERENKOV J.A. - Structure of the Interface in Stratified Flow. Heat Transfert Soviet Research, 1969, Vol. 1, No. 6, pp. 153-1 58.

[25] PEDERSON Fl. B.O. - Discussion, Two-Dimensional Surface Warm Jets. Proc. A.S.C.E., 1972, Vol. 98, No. HY2 pp. $397-398$

[26] PEDERSON Fl. B.O. - Interfacial Mixing in Two Layer Stratified Flow. Inst. Hydrodyn. and Hydraulic Eng., Report No. 74, 1974.

[27] SCHLICHTING H. - Boundary Layer Theory. McGraw-Hill Book Co. Inc., New York, Toronto, London, Verlag G. Braun, Karlsruhe, 4th Edition, 1960, pp. 534-565.

[28] SILBERMAN E. - Discussion, Surface Discharge of Horizontal Warm-Water Jet. Proc. A.S.C.E, 1967, Vol. 93, No. PO1, pp. 153-155.

[29] SPRONG T.A. - Menging bij Dichteidsverschillen, Momentum and Mass Transfer in Stratified Flow. Report R88, Delft Hydraulics Laboratory, 1974.

[30] STEFAN H. - Stratification of Flow from channel into Deep Lake. Proc. A.S.C.E., 1970, Vol. 96, HY7, pp. 14171434.

[31] STEFAN H. - Dilution of Buoyant Two-Dimensional Surface Discharges. Proc. A.S.C.E., 1972, Vol 98, No HY1, pp. 71-86.

[32] STEFAN H. and SCHIEBE F.R. - Heated Discharge from Flume into Tank. Proc. A.S.C.E., 1970, Vol 96, No. SA6, pp. 1415-1433.

[33] STOLZENBACH K.D. and HARLEMAN D.R.F. - An Analytical and Experimental Investigation of Surface Discharges of Heated Water. M.I.T., Report No. 135. 1971.

[34] SUGA K. - Salt-Wedge Intrusion with entrainment. I.A.H.R., D22, Sao Paulo, 1975, pp. 172-179.

[35] TAMAI N., WIEGEL R.L. and TORNBERG G.F. Horizontal Surface Discharge of Warm Water Jets. Proc. A.S.C.E., 1969, Vol. 95, No. PO2, pp. 253-276.

[36] WADA A. - A Study of Mixing Process in the Sea caused by Outfall of Industrial Waste Water. Coastal Eng, in Japan, 1969, Vol. 12, pp. 147-158.

[37] WILKINSON D.L. and WOOD I.R. - A Rapidly Varied Flow Phenomenon in a Two-Laver Flow. J. Fluid Mech., 1971, Vol. 47, Part w, pp. 241-256. 